
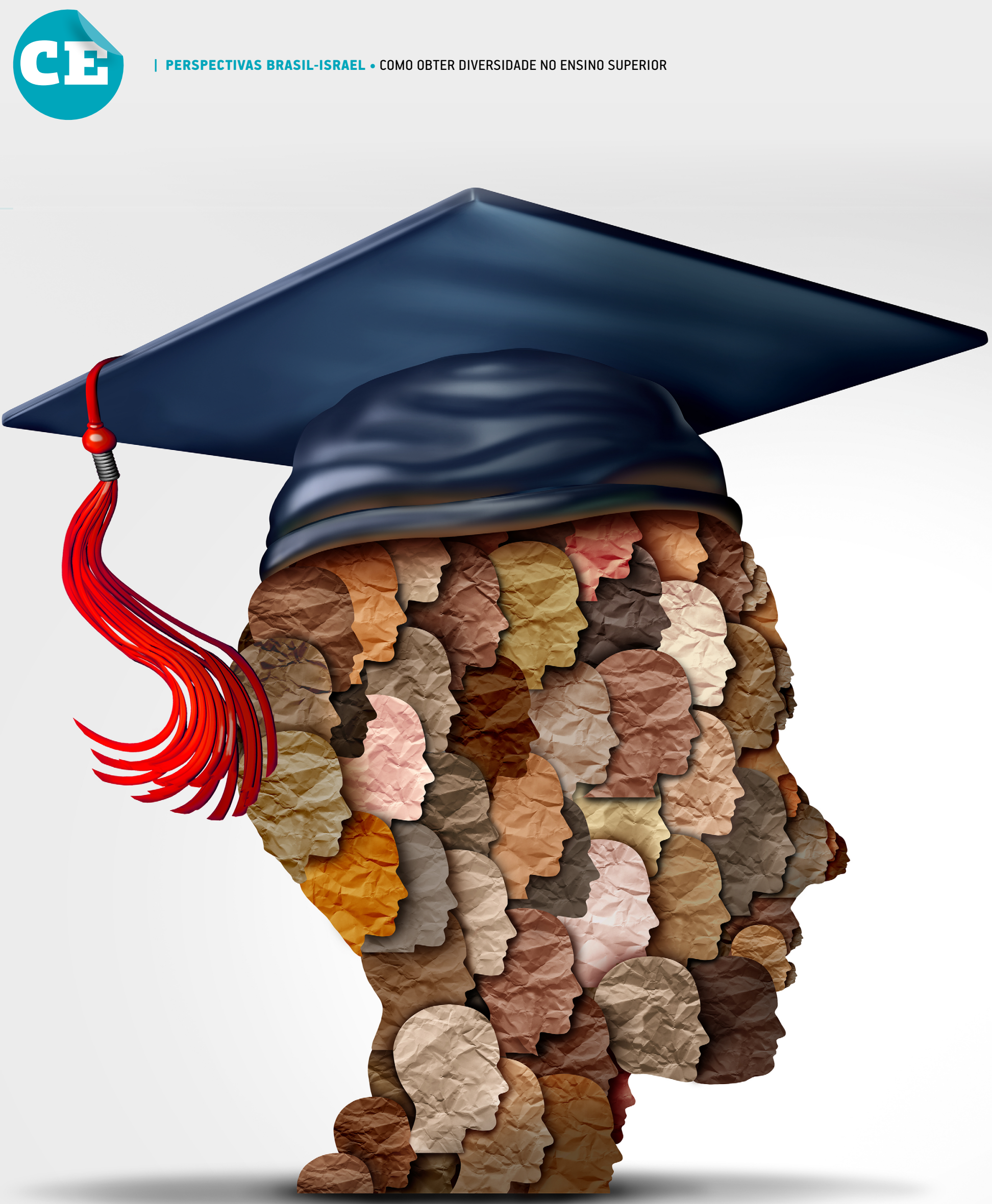


\section{COMO OBTER DIVERSIDADE NO ENSINO SUPERIOR}

| POR TALI HADASA BLANK

\section{O Hadassah Academic College construiu expertise na inclusão de árabes israelenses e judeus ultraortodoxos na universidade, dando atenção individualizada e preparando os alunos para obter bons empregos ou abrir uma startup após a graduação.}

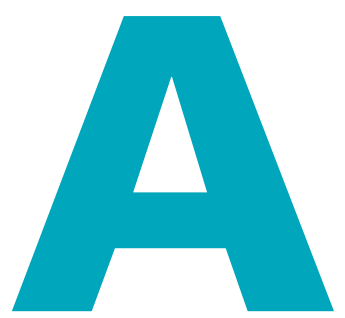

economia de Israel enfrenta um dilema: enquanto o índice oficial de desemprego é de apenas $8 \%$, a taxa de participação da força de trabalho do país está longe do ideal e ronda os $60 \%$. Por que esse contraste acontece? A resposta a essa pergunta está relacionada ao comportamento de dois grupos: os árabes israelenses e os judeus ultraortodoxos.

A população árabe israelense chega a 25\% dos 9,3 milhões de habitantes do país, mas sua participação no mercado de trabalho está longe de ser satisfatória, principalmente entre aqueles com menor nível educacional. Quanto aos trabalhadores com nível superior, a maioria está empregada no setor público e apenas uma pequena minoria trabalha em indústrias avançadas, como a de alta tecnologia.

Já o grupo de judeus ultraortodoxos inclui aproximadamente 1,2 milhão de pessoas e sua taxa de emprego entre o sexo masculino é de cerca de $48 \%$. Aproximadamente $23 \%$ dos homens ultraortodoxos empregados trabalham na educação, muitas vezes sem formação acadêmica ou treinamento após o ensino secundário, exceto estudos religiosos. Isso ocorre porque os homens ultraortodoxos geralmente dedicam a vida ao estudo da religião e, como consequência, as mulheres sustentam o lar. A taxa de emprego entre as mulheres é superior a $70 \%$ e sua participação em cargos tecnológicos que exigem ensino superior está em ascensão, enquanto aquela no setor de educação está em declínio, com uma queda de 58\% em 2004 para $46 \%$ em 2017. São dados que indicam uma mudança na preferência profissional das mulheres e seu desejo de ganhar salários mais altos, que muitas vezes estão disponíveis na indústria de alta tecnologia.

Ambos os grupos, árabes israelenses e ultraortodoxos, são caracterizados por níveis educacionais relativamente baixos, alta taxa de fertilidade (mais de quatro filhos em média por família), baixa taxa de participação no mercado de trabalho e normas culturais muito conservadoras. Por exemplo, uma muçulmana árabe religiosa usa o hijab, cobrindo cabelo, cabeça e peito, na presença de qualquer homem fora de sua família imediata. Na mesma linha, uma ultraortodoxa irá trabalhar apenas em organizações que respeitem seu desejo de compartilhar o espaço de escritório com outras mulheres e não com homens. Normas culturais podem desafiar esses dois grupos, principalmente as mulheres que desejem participar do mercado de trabalho. 


\section{INICIATIVAS DO HADASSAH ACADEMIC COLLEGE}

Localizado no centro de Jerusalém, o Hadassah Academic College (HAC) responde aos desafios culturais de árabes israelenses e de judeus ultraortodoxos. Ao contrário de outras instituições de ensino superior, o HAC desenvolveu a capacidade de acomodar essas populações que, até anos recentes, tinham acesso restrito à universidade. Além disso, a faculdade concentrou-se em programas para orientar a carreira profissional e em preparar os alunos para obterem bons empregos após a formatura. O resultado é que hoje o HAC é uma das faculdades que mais crescem em Israel, com uma população estudantil de aproximadamente 6 mil alunos.

Em 2012, o HAC estabeleceu uma filial ultraortodoxa, o Strauss Campus, localizado em um bairro ultraortodoxo de Jerusalém. O campus Strauss possui duas escolas, uma para mulheres e outra para homens. A escola feminina atualmente tem cerca de 540 alunas estudando para o bacharelado em biotecnologia, optometria, ciências laboratoriais médicas, distúrbios da comunicação, gestão, ciência da computação e serviço social. A escola masculina tem cerca de 180 alunos estudando para o bacharelado em ciência da computação, administração e serviço social. Desde a criação do campus, cerca de 500 mulheres e de 100 homens receberam diploma de bacharelado e foram integrados em cargos importantes na indústria privada, no setor público e na sociedade civil.

Outra ação importante foi a criação de três centros diferentes, cada um acomodando grupos minoritários e facilitando sua integração no mercado de trabalho:

- Centro de Aconselhamento de Carreira. Os alunos do HAC estudam em programas de graduação voltados para a prática e são preparados para entrar no mercado de trabalho após a formatura. Um a cada três alunos obtém orientação e participa dos workshops do centro, e mais de mil alunos comparecem à Feira de Emprego da Primavera, que ocorre anualmente. O programa de estágio recém-ampliado permite que um número significativo de alunos ganhe uma valiosa experiência por meio do treinamento prático. É um programa ganha-ganha, com os alunos obtendo experiência de trabalho e a organização recebendo recursos gratuitos para atingir seus objetivos. O sucesso dessa investida levou o centro a expandir seus serviços e começar a ajudar os ex-alunos do HAC, oferecendo seminários de busca de emprego e workshops de networking nas redes sociais. Os serviços que esse centro oferece respondem ao desafio de aumentar a participação dos israelenses na força de trabalho e sustentam a

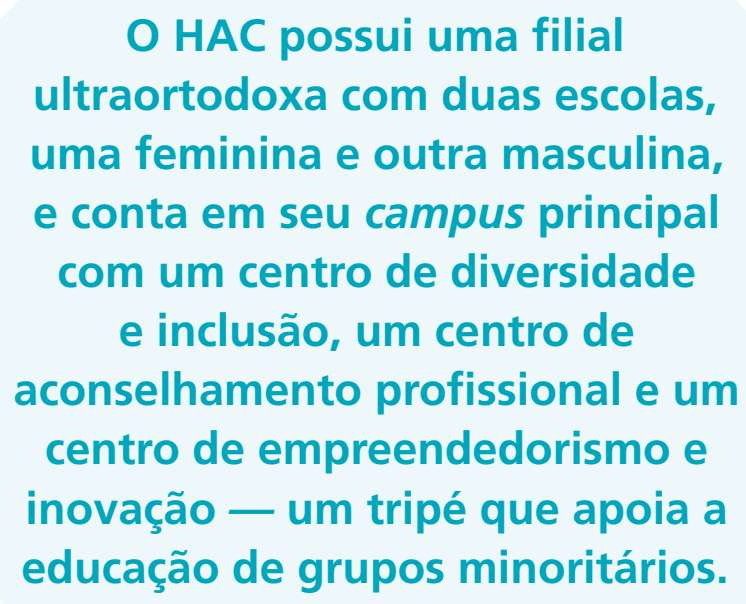

O HAC possui uma filial ultraortodoxa com duas escolas, uma feminina e outra masculina, e conta em seu campus principal com um centro de diversidade e inclusão, um centro de aconselhamento profissional e um centro de empreendedorismo e inovação - um tripé que apoia a educação de grupos minoritários.

vantagem competitiva do HAC (ver indicadores no quadro), e podem servir de modelo para outras instituições acadêmicas em Israel e ao redor do mundo.

- Centro de Diversidade e Inclusão. A população do HAC é altamente diversificada e inclui mais de $70 \%$ de mulheres e cerca de $25 \%$ de estudantes árabes israelenses. O centro de diversidade e inclusão é o primeiro do gênero no ensino superior de Israel. Professores e funcionários fornecem atenção individualizada e apoiam alunos de origens desprivilegiadas, sub-representadas e minorias, incluindo ultraortodoxos, árabes-israelenses, etíopes-israelenses e novos imigrantes. $O$ centro também ajuda a integrar alunos com deficiências físicas e de aprendizado e aqueles com problemas emocionais. O HAC oferece um ambiente de aprendizagem culturalmente inclusivo para seu corpo discente diversificado e providencia o conhecimento e as habilidades de que este precisa para construir uma carreira de sucesso, buscando excelência acadêmica via instrução, bolsas de estudo e pesquisa. Enquanto muitas instituições acadêmicas reivindicam diversidade e inclusão, o HAC faz isso com grande sucesso. No início deste ano, 32 alunos participaram do quinto Programa Anual de Diálogo Judaico-Árabe, um curso eletivo com atividades conjuntas para estudantes judeus e árabes israelenses que foi projetado para criar familiaridade com as culturas uns dos outros, quebrar estereótipos e promover a sensibilidade cultural. Neste ano, os participantes encerraram o programa, que contempla eventos musicais, viagens de campo e aventuras culinárias, com um workshop de artes em que criaram uma fonte hebraico-árabe integrada para a palavra "juntos" para expressar sua recém-aprendida linguagem compartilhada de res- 


\section{RESULTADOS DO HADASSAH ACADEMIC COLLEGE}

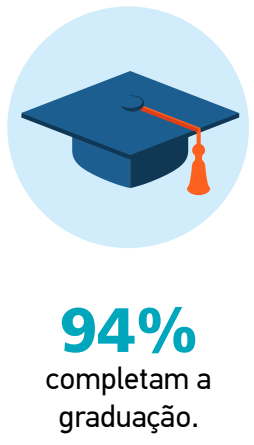

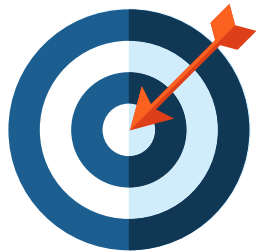

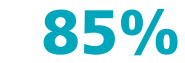

encontram emprego

no campo de formação.
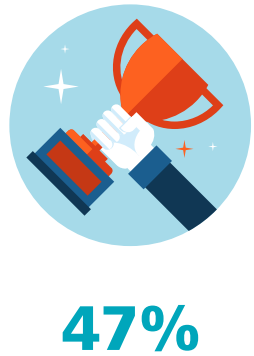

são os primeiros da família a cursar o ensino superior.

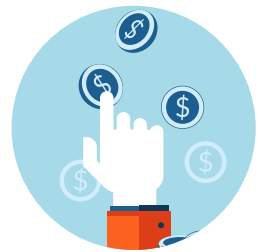

$21 \%$

recebem ajuda financeira do $\mathrm{HAC} \mathrm{e}$ de seus doadores. peito. Essas ações reforçam o posicionamento do HAC como uma instituição acadêmica que propicia a integração das diferentes partes da população israelense e as conecta para um futuro econômico melhor.

- Centro de Empreendedorismo e Inovação. O Centro Blender foi lançado em março de 2021 e serve como uma estrutura na qual os alunos podem criar e desenvolver novos negócios e empreendimentos sociais. Foi fundado por Tali Hadasa Blank, uma palestrante sênior que estuda inovação e empreendedorismo, com Michael Berman, chefe de ciência da computação e fundador de quatro empreendimentos de tecnologia na indústria médica. O Blender oferece um programa metódico e sistemático que cria oportunidades para encontros entre empreendedores e inovadores de diferentes origens religiosas, culturais e étnicas, e em diferentes áreas de especialização, incluindo ciência da computação, biotecnologia, design industrial, comunicação fotográfica, optometria, gestão. O objetivo do Blender é fornecer conhecimento, suporte e ambiente de trabalho, permitindo assim o desenvolvimento de novos empreendimentos e conectar a comunidade do campus do HAC ao ecossistema empresarial e social de Jerusalém e de Israel.

Como o próprio nome indica, o Blender é um lugar em que alunos e ex-alunos do HAC de diferentes origens e áreas de especialização podem trabalhar juntos, cada um trazendo seu sabor único para a mistura (blend, em inglês), criando combinações novas. O foco do programa está em tópicos essenciais para transformar um conceito inicial em uma iniciativa viável.

Os programas são feitos sob medida para as diversas comunidades do HAC. Por exemplo, há dois programas se- parados de pré-aceleração de startups para os judeus ultraortodoxos (um para mulheres e outro para homens). O objetivo do programa é fornecer e facilitar a aquisição de ferramentas, o compartilhamento de conhecimento e inspirar os alunos a criar ideias bem definidas que podem levar ao desenvolvimento de inovações e/ou negócios sustentáveis.

\section{CONCLUSÃO}

O HAC é um exemplo de instituição acadêmica que reconhece que o desafio da diversidade e da inclusão pode e deve ser superado. $O$ potencial da força de trabalho israelense está longe de seu nível ideal. A abordagem ativa do HAC com seu campus para a comunidade ultraortodoxa e o estabelecimento de três centros diferentes fornecem uma boa resposta aos grupos sub-representados no mercado de trabalho israelense. Embora o produto interno bruto (PIB) de Israel tenha valores impressionantes (407 bilhões de dólares em 2020, o que significa um PIB per capita de 44.486 de dólares), o atual crescimento da economia é menor do que poderia ser. As ações do HAC podem facilitar a integração de grupos minoritários e permitir uma melhor utilização do potencial de força de trabalho.

\footnotetext{
PARA SABER MAIS:

Eran Yashiv e Nitsa Kasir (Kaliner). The labour market of Israeli Arabs: key features and policy solutions. Policy Insight, n.78, 2015. Disponivel em: cepr.org/sites/default/files/ policy_insights/Policylnsight78.pdf

Avi Weiss. The labor market: a general picture. Taub Center for Social Policy Studies in Israel, 2020. Disponivel em: taubcenter.org.il/en/research/israels-labor-market-an-overview/

Israel GDP — Gross Domestic Product. Countryeconomy.com. Disponivel em:

countryeconomy.com/gdp/israel

TALI HADASA BLANK > Professora sênior e Coordenadora de Inovação e Empreendedorismo do Management Department do Hadassah Academic College > talibl@hac.ac.il
} 